\title{
https://doi.org/10.48009/1_iis_2005_183-189 \\ E-STUDENT RETENTION: FACTORS AFFECTING CUSTOMER LOYALTY FOR ONLINE PROGRAM SUCCESS
}

\author{
Queen E. Booker, Minnesota State University, Mankato, queen.booker@mnsu.edu \\ Carl M. Rebman, Jr., University of San Diego, carlr@sandiego.edu
}

\begin{abstract}
The Internet revolution has had a major impact on higher education. If a public institution of higher learning has not engaged in online courses, it will if for no reason other than to meet customer demand [8]. But despite this customer demand, institutions are reporting low retention rates in continuing enrollees (students who enroll for online classes for a second semester) or students completing the classes. This study looks at several factors that affect student satisfaction and retention by reviewing survey results from students who enrolled in at least one online class at the University of Arizona during the academic years 2001-2003. The study also looks at student demographics and compares the retention and performance. The results indicate that certain combinations of online course material, teacher quality and general online access quality as being the major factors that discouraged students from completing the course or enrolling in another course.
\end{abstract}

Keywords: Online learning Techniques, Distance Online Education, Online Learning Pedagogical Studies

\section{INTRODUCTION}

The Internet revolution has been cited as the biggest change to hit business since currency replaced barter [9]. According to Reichheld, no new business tool has generated more anticipation. For higher education administrations, the tool represents an opportunity to attract more and a different type of student through the offering of online education programs. In fact, a recent article in Education and Training states that around 86\% of regular Internet users would like to improve their skills and knowledge through online education. In addition, distance education course offerings and enrollment have nearly doubled between 1994-95 and 1997-98, as have the number of degree and certificate programs offered

[http://www.ed.gov/PressReleases/12-1999/distance.html]. This acceleration appears to be continuing as the National Center for Education Statistics has recently reported that 56 percent of all 2-year and 4-year Title IV-eligible, degree-granting institutions offered distance education courses in 2000-2001 and another twelve percent of all institutions indicated that they planned to start offering distance education courses in the next 3 years [10].

This paper examines from the student perspective what makes a successful online course and what an institution must pursue to create and maintain a loyal set of online students and why this golden rule of business is so important to ensure the success of online programs.

\section{ONLINE EDUCATION PROGRAM SUCCESS}

Less then ten years ago online education was the key phrase in higher education. It was a potential trillion-dollar market wrapped around the prospect of learning anytime, anywhere. Despite the promise of the what technology can offer the world in terms of lifelong learning, cynics have had a field day, claiming that online education has been just one more fad, little 
more than a reprise of the dot-coms' bursting bubble, exhibiting more hype than substance [http://www.thelearningalliance.info, 12]. The private sector has been able to grasp a large portion of the online education market, but public institutions, with which the costs would be expectantly less, have yet to capture a reasonable share of this potential.

\section{RESEARCH STUDY METHODOLOGY}

This study was designed to understand student perceptions about online courses and the student's proclivity to take additional courses online as a measurement of online student retention. Additionally, the factors used in the study were to determine correlation between consumer patronage and potential for customer loyalty.

\section{Research Hypotheses}

The study was divided into two parts. In Part I of this study, students' continual enrollment in additional online courses was tested to determine if it the decision to enroll was influenced by students' perception of flexibility, technology, and value. In Part II of this study, students' actual completion of online courses was assessed to find out if it was related to their demographics, course material richness, technology availability, perceived teacher quality, and/or course type.

Therefore, the following hypotheses were established to test the relationships.

H1: Students' perception of online course technology will have no effect on their desire to enroll in an additional online course.

H2: Students' perceptions of online course flexibility will have no effect on their desire to enroll in an additional online course.

H3: Students' perception of online course value will have no effect on their desire to enroll in an additional online course.

H4: Students' demographics have no significant influence on their decision or ability to complete an online course.

H5: Material media richness has no significant influence on a student's decision or ability to complete an online course.

H6: Consistency and continual availability of the online course technology has no significant influence on a student's decision or ability to complete an online course.

\section{Variables Studied}

\section{RESEARCH DESIGN}

In Part I of this study, the dependent variable of enrollment in two or more courses was correlated to the independent variables of students' perception of educational course technology and general knowledge of and experience with information technology. In the students' perception dimension, the following items were tested to see the interrelationship with each other. These items include years of experience with educational course technologies, technologies used, and first exposure to course technologies. In the information technologies knowledge dimension, students' knowledge about selected technologies was tested to see the interrelationship with each other.

In Part II of this study, the dependent variable of completed online course was correlated to the independent variable of students' commitment to continued enrollment in online courses 
(patronage). Patronage was tested through the number of additional courses completed, length of time between enrollments, and attitude changes since enrollment in the first online course. The reported potential for continual patronage was assessed through age, satisfaction, and quality of courses since first-time enrollment.

Table 1 shows the number of valid surveys that were used in the study. The table shows the number of students who actually enrolled in online courses and the number of students actually completing online courses. Although attempts were made to ensure no duplicate surveys were collected, a bias must be noted that some students may have completed the survey more than once.

\begin{tabular}{|r|l|l|}
\hline $\begin{array}{l}\text { Number of } \\
\text { Online } \\
\text { Courses }\end{array}$ & $\begin{array}{l}\text { Number } \\
\text { Students } \\
\text { Enrolled }\end{array}$ & $\begin{array}{l}\text { Number } \\
\text { Students } \\
\text { Completing } \\
\text { Course }\end{array}$ \\
\hline 0 & 1012 & 1307 \\
\hline 1 & 522 & 445 \\
\hline 2 & 406 & 212 \\
\hline 3 or more & 60 & 36 \\
\hline Total & 2000 & 2000 \\
\hline
\end{tabular}

Table 1. Student Enrollment versus Completion in Online Courses

Courses most often taken online were history (22\%), business (34\%), and social sciences (26\%).

\section{Survey}

The survey measurements were as follows:

Potential for customer loyalty. If the student completed an online course, the student was asked to respond whether or not they would take or had taken another online course, and if given a choice would they take the course at the University or at another institution. Further the students were asked to indicate his/her agreement/disagreement to concepts such as the 24 hour/365 opening, perceive lower costs, efficiency gains, fewer hassles, and private learning. Students were also asked if they would recommend the course to another student or person.

Material/medium effectiveness. If the student had completed the course, the student was asked to supply course name and the grade. Items were included in the five-point Likert scale portion of the survey where the respondent had to indicate the extent of his or her agreement/disagreement based on student involvement and participation, cognitive engagement, technology self-efficacy, perceived usefulness of the technology employed, and the relative advantage of online delivery. A material effectiveness index was subsequently built by adding the value of the items.

Technology. Technology questions related to the ease of use, the availability, and the timeliness of responses. A set of items was developed using a five-point Likert scale to capture the opinions and a technology index was subsequently built by adding the value of the items. 
Student characteristics. In addition to a question relating to previous computer experience, the following demographic variables were included in the analysis: access to the Internet at home, program of study followed by the ethnicity, gender, marital status, working status, and whether or not the person had children at home.

\section{Data Reduction}

Data reduction was conducted by using factor analysis. The instrument was designed to include five dimensions as independent and dependent variables. They were students' perceptions of the technology (availability, media richness), students' perception of course value that online courses could provide, retention-1 defined as the student completing more than one online course (independent variable dimensions), retention-2 defined as the student willingness to take more than one online course (independent variable dimensions) or student demographics (dependent variable dimension). However, the preliminary study found out that using factor analysis to regroup each individual variable is more explainable and significant in terms of their common underlying dimensions. This statistical approach is used to analyze the interrelationship among a large number of variables and find a way of condensing the information contained in a number of original variables into a smaller set of dimensions (factors) with a minimum loss of information.

After the factor analysis, reliability test was conducted. Coefficient (Cronbach's) Alpha is a measure of reliability or internal consistency [3]. Values of Cronbach's Alpha of .50 or above, is consistent with the recommended minimum values stated by Nunnally [1967]. Cronbach's alpha indicating reliability for each factor groupings showed that four factors were acceptable level of alpha, factor 1 Demographics $(\alpha=.82)$, factor 2 Environment $(\alpha=.60)$, factor 3 Course Quality $(\alpha$ $=.53)$ and factor 4 Customer Loyalty $(\alpha=.51)$.

\section{Data Analysis}

\section{DATA ANALYSIS AND RESULTS}

The data from the survey were analyzed using multiple regressions to develop a path analysis diagram to ascertain the factors most important for student retention in online courses. In order to complete this path diagram, several regression equations were analyzed. The variables were compiled from the factor analysis and computed from various questions in the survey instrument.

\section{HYPOTHESES TESTING}

The original hypotheses and results are discussed below.

H1: Students' perception of online course technology will have no effect on their desire to enroll in an additional online course. Based on the regression of more than one course completed, this hypothesis can be rejected. The students' reaction to online course technology had a definite impact on their desire to enroll or recommend a course to another student. Despite flexibility and convenience of online courses, rich media (streaming video) was not desirable quality for the online course, having a negative coefficient (-.12) and high p-value (.03) for taking a second course.

H2: Students' perceptions of online course flexibility will have no effect on their desire to enroll in an additional online course. Based on the regression of more than one course completed and the factors affecting course satisfaction (synchronous versus asynchronous; media richness; 
teacher response types (email, chat, discussion board); assessment type, this hypothesis was also rejected. The regression equation resulting from this analysis had an R-value of .63, and synchronous courses (1) had a negative coefficient which was significant at .05. Further, media richness with video had a negative coefficient as was determined in the regression for H1. Other factors with a negative coefficients and significant $\mathrm{p}$-values included response type of discussion board, Powerpoint only material. Assessment type was not significant in the decision.

H3: Students' perception of online course value will have no effect on their desire to enroll in an additional online course. Based on the regression of more than one course completed and factors affecting value, this hypothesis was accepted. The resulting regression equation had an $\mathrm{R}-$ squared value of .09. Further, no variable in the equation had a significant $p$-value on the coefficient below .1. This could be explained that the online courses were the same price as a traditional course.

H4: Students' demographics have no significant influence on their decision or ability to complete an online course. Based on the regression of more than one course completed and the student demographics, including technology proficiency, the hypothesis was rejected. Factors having significant $\mathrm{p}$-values at or below the .10 level included age, marital status, children (y or n), work status, high comfort with technology, and access to the Internet at home.

H5: Material media richness has no significant influence on a student's decision or ability to complete an online course. Based on the regression of more than one course completed and the type of media provided for the course, this hypothesis was also rejected. Type of media (video) had a negative coefficient on the students' decision to take another online course. This could be correlated to the type of Internet connectivity available to the student most likely to take a second course or recommend an online course to someone else. The demographics of the student were older than 22, working at least part time, had no children, some technology proficiency and Internet access at home. The most common type of Internet access was dial-up, which could explain the lack of comfort with the video streaming course content.

H6: Consistency and continual availability of the online course technology has no significant influence on a student's decision or ability to complete an online course. Based on the regression on completed online courses and availability of the overall technology (technology failed fewer than five times when online), types of availability (synchronous versus asynchronous), types of access to material (always available versus available as determined by instructor), and perceived teacher availability, this hypothesis was rejected. All the factors were significant at or below the .15 level, with type of availability and perceived teacher availability significant at the .05 level.

\section{FINDINGS}

The purpose of this study was to identify factors important to retaining the online learner as a loyal customer for institutions of higher learning. Based on the Volery and Ford study [11], quality of content, assessment material, and costs were presumed to be necessary components for student retention.

The first step was to identify the demographics for the ideal online learner the purpose of building online customer retention. For this study, the focus was primarily on students 
completing two or more courses online, which may be different from the traditional definition of the retained student. The second step was to identify those factors that were considered significant to retaining the student.

The first and most interesting outcome was that students over the age of 22 who were working actually preferred taking their courses online and would not only recommend it but also enrolled in more courses online even though their mean overall course quality score was only slightly better than neutral. The second interesting outcome overall was that females rated their participation satisfaction (3.9) higher than the males (2.9). The means got closer as the age increased. Next, the quality of the online material had an important effect on student satisfaction and decision to take a second or more courses. The video material, despite its perceived richness, was not as highly rated as the PowerPoint with examples and audio. The highest rated material was anything with examples. Lecture material, if accompanied by a book, was considered useless. However, lecture material if not accompanied by a book was considered wonderful (4.2). This factor may be perceived as a lower cost, although it was not specifically measured in the study.

However, most students were dissatisfied with communication with the instructor (2.2), the amount of time it took to download lecture material (2.1), with the quality of support if the technology failed (1.7). The variances between the scoring for these questions were $.3, .2$, and .5 respectively. A t-test on the results indicates these factors are significant to the students in terms of future enrollment.

\section{LIMITATIONS AND FUTURE RESEARCH}

This study was limited to students at the University of Arizona. The original questions were developed without the benefit of customer satisfaction studies for e-commerce which could improve the data collection. The next step would be to improve the survey to include actual questions from studies such as Lin [4] and $\mathrm{Lu} \mathrm{[5]} \mathrm{as} \mathrm{well} \mathrm{as} \mathrm{expand} \mathrm{the} \mathrm{survey} \mathrm{to} \mathrm{other} \mathrm{campuses}$ as well as update the survey for the University of Arizona students to determine if perceptions towards e-education are changing as rapidly as technology. Further, the study did not collect data on type of access to the online technologies (DSL versus dial-up versus cable-modem) nor did it compare access via direct connection to the University technologies versus using a secondary Internet service provider (ISP). Also, the technologies for online education has improved significantly in the past two years and more students are gaining access to educational technologies earlier in their K-12 experiences. A second study needs to be conducted along with the addition of questions from e-commerce surveys and among a wider range of students. The surveys from the University of Arizona were collected based on trust. A solicitation of surveys from confirmed online course students would provide a more comprehensive and less biased perception of what is necessary to retain students. But this beginning study is a step in helping public institutions think of the online market not only as a way to increase enrollment in the general education programs but as an opportunity to continue to expand lifelong learning opportunities for the community at large.

\section{CONCLUSION}

Retaining the online student as a business strategy is not an often discussed approach to online education. Yet the fact remains that with the wealth of knowledge contained within the walls of 
an academic institution, online education can be a profitable market. But the issue of student retention remains a fact. Younger students need to be eased into online learning as they currently perceive technology as a toy, not as a tool for learning, and use online technologies to remain connected to family and friends. Perhaps one strategy would be to have the students participate in hybrid courses during the formative (freshman and sophomore years) and limit full online courses to the latter years (sophomore, junior and senior), creating the perception of online education as an opportunity for learning at the University even upon graduation. Secondly, clearly the older student is a profitable target audience. Given their experiences with certain courses, most students 22 and older were interested not only in taking more courses online but also expressed an interest in taking courses simply for the fun because of the convenience (anytime), fewer hassles (not having to sit and listen to younger students), and streamlined process if the courses were fully contained (not having to buy books or having to go to multiple websites just to get key information). They were also willing to recommend courses to others.

Also, the study debunks the conclusions for e-commerce when it comes to the online education market. Unlike the e-commerce customer, technical orientation was not as significant a factor as expected. This could be attributed to the improved interfaces of Blackboard and the improved technical expertise of faculty on how to use them.

\section{REFERENCES}

1. Bradshaw, D., \& Brash, C. (2001). Managing Customer Relationships in the e-business world: how to personalize computer relationships for increased profitability. International Journal of Retail and Distribution Management, 29(11/12), 520-529.

2. Collis, B. (1996). Tele-Learning in a Digital World. London: Int'l Thomson Computer Press.

3. Cronbach, L.J. (1951). Coefficient Alpha and the internal structure of tests. Psychometrika, 16(October), 297-334.

4. Lin, C. C. (2003). A Critical Appraisal of customer satisfaction and e-commerce. Managerial Auditing Journal, 18(3), 202-212

5. Lu, J., (Sept 2003). A Model for Evaluating E-Commerce Based on Cost-Benefit and Customer Satisfaction. Information Systems Frontiers, 5(3), 265-277.

6. Nickerson, R. S. \& Zodhiates, P.P. (1998). Technology in education: Looking toward 2020: Hillsdale, NJ: Erlbaum.

7. Nunnally, J.C. (1967). Psychometric theory. New York: McGraw-Hill.

8. Poehlein, G. W. (1996). Universities and information technologies for instructional programmes: Issues and potential impacts. Technology Analysis and Strategic Management, 8(3), 283-291.

9. Reichheld, F., Markey R., \& Hopton, C. (2000). E-customer loyalty - applying the traditional rules of business for online success. European Business Journal, 12(4), 173-179.

10. Tabs, E.D., Waits, T., Lewis, L., \& Greene, B. (2003). Distance Education at Postsecondary Education Institutions: 2000-2001 (NCES 2003 -017). U.S. Department of Education, National Center for Education Statistics, Washington, DC: U.S. Government Printing Office.

11. Volery, T., \& Lord, D.(2000). Critical success factors in online education. The International Journal of Educational Management, 14(5), 216-230.

12. Zemsky, R \& Massy W. (2004). Why the E-Learning Boom Went Bust. Chronicle of Education, 50(44), pB6, 3p. 